\title{
A INSERÇÃO DOS MOVIMENTOS INDÍGENAS NA ARENA POLÍTICA BOLIVIANA: NOVOS E VELHOS DILEMAS
}

BRUNO SIQUEIRA ABE SABER MIGUEL ${ }^{1}$

$U N B$

\begin{abstract}
RESUMO: Tendo como objeto os movimentos indígenas bolivianos, o trabalho explora a articulação feita por esses grupos entre o universo simbólico e o universo instrumental, conforme concepção de Alain Touraine, abordando questões relacionadas à problemática histórica de sua exclusão e a forma pela qual este quadro se refletiu no cenário político boliviano, analisando as condições que propiciaram a atual ascensão política dos movimentos indígenas. Como será visto, apesar de os movimentos indígenas terem adquirido certa projeção política no cenário boliviano, a persistência de um padrão de governo que não contempla e formação de espaços públicos de aprofundamento da democracia e a presença de obstáculos como as divisões regionais ainda impõem sérios riscos para a consolidação da democracia no pais.
\end{abstract}

PALAVRAS-CHAVE: Bolivia; movimentos sociais; movimentos indígenas; democracia.

ABSTRACT: Considering the Bolivian indigenous movements, the article explores the unification made by these groups between the symbolic and the instrumental universe according to the concepts of Alain Touraine -, analyzing questions related to their historical exclusion and how this situation reflects in the Bolivian political scene, also examining the conditions that had enabled the current political emergence of the indigenous movements. Although the projection acquired by the indigenous movements, the persistence of a government standard that doesn't prioritize the constitution of public spaces to deep democracy and the presence of obstacles as the regional divisions still impose serious risks for the consolidation of the democracy in the country.

KEYWORDS: Bolivia; social movements; indigenous movements; democracy.

\section{Um breve retrato socioeconômico dos povos indígenas bolivianos}

De acordo com o último censo populacional do Instituto Nacional de Estatísticas (INE) da Bolívia, realizado em 2001, cerca de dois terços da população do país é composta por indivíduos de origem indígena, compreendendo 35 diferentes povos, dentre os quais se destacam as

\footnotetext{
${ }^{1}$ Mestrando em Ciências Sociais no Centro de Pesquisa e Pós-Graduação sobre as Américas (CEPPAC), Universidade de Brasília. E-mail: brunoabesaber@yahoo.com.br .
}

Espaço Ameríndio, Porto Alegre, v. 2, n. 1, p. 68-84, jan./jun. 2008. 
BRUNO SIQUEIRA ABE SABER MIGUEL - A inserção dos movimentos indígenas ...

etnias quéchua e aymará, residentes, sobretudo, na zona rural do altiplano andino (departamentos de La Paz, Potosí, Oruro, Chuquisaca e Cochabamba) e que, em conjunto, respondem por quase $56 \%$ desse total; as outras etnias encontram-se dispersas pelo país, adquirindo relevo os grupos guaranis e mojeños, habitantes das chamadas terras baixas bolivianas (departamentos de Santa Cruz, Beni, Pando e Tarija).

No entanto, apesar desta larga representatividade demográfica, os povos indígenas enfrentam um grave quadro de vulnerabilidade, traduzida não somente pela menor parcela da renda nacional auferida por eles, como também pela histórica baixa representatividade deste grupo no cenário político do país e pelas más condições sociais em que se encontram.

De fato, a pobreza afeta os indígenas de forma muito mais acentuada do que outros grupos da sociedade ${ }^{2}$, o que pode ser ilustrado, em parte, pelo fato de que $67 \%$ dos empregos mais vulneráveis e precários - onde as remunerações são mais baixas ou até mesmo inexistentes - são ocupados por indígenas, demonstrando como o elemento étnico constitui um objeto de exclusão e desvalorização social no país. Posto de outra forma, enquanto a renda média de um indivíduo que tem no castelhano seu idioma materno chega a 931 bolivianos, um indígena de origem quéchua aufere uma renda média de 236 bolivianos, ou seja, quase cinco vezes menos (INE, 2001).

No campo educacional, apesar da institucionalização da educação intercultural bilíngüe, em 1992, que reconhece a heterogeneidade étnica do país ${ }^{3}$, aproximadamente $25 \%$ dos indígenas bolivianos não têm nenhuma instrução formal, em contraste com uma situação vivenciada por $14 \%$ da população não-indígena. Além disso, as taxas de desnutrição e mortalidade verificadas em crianças com menos de cinco anos provenientes de domicílios indígenas bolivianos são as maiores da América do Sul, reflexo da precária disponibilidade de serviços essenciais, como água potável, saneamento básico e centros de saúde, obrigando a população indígena a buscar nas práticas tradicionais a

\footnotetext{
${ }^{2}$ Segundo dados do INE (2001), 80\% da população indígena vive abaixo da linha de pobreza, enquanto que, por outro lado, $40 \%$ da população não-indígena encontra-se nesta mesma situação.

${ }^{3}$ Esta reforma educacional, aprovada pela lei $\mathrm{n}^{\circ} .1565$, estabelece que os indígenas têm o direito de serem educados em sua língua materna, de modo a gerar, assim, as condições para sua integração na sociedade boliviana com base em sua identidade cultural.
} 
BRUNO SIQUEIRA ABE SABER MIGUEL - A inserção dos movimentos indígenas ...

cura para as doenças que a aflige, sobretudo a malária, a tuberculose e o sarampo (FERNÁNDEZ, 2004).

Confrontadas com esta situação, muitas famílias desenvolveram numerosas redes sociais, associadas principalmente ao mercado de crédito, que passaram a funcionar como mecanismos de apaziguamento do quadro de pobreza em que vive grande parte da população indígena boliviana ${ }^{4}$. Neste sentido, vale ressaltar o caso da cidade de El Alto, outrora um bairro da capital La Paz e que hoje possui mais de 650 mil habitantes, em sua maioria de origem aymará, dedicados, sobretudo, ao comércio informal e ao trabalho artesanal, nos quais os fortes laços comunitários constituem um traço marcante das associações de crédito criadas pelos povos indígenas como estratégias de redução da pobreza.

Como se pode apreender pelo que foi dito, o governo boliviano tem se mostrado incapaz de atender às demandas sociais de grande parcela da população, o que se refletiu, ao longo do tempo, em crises de governabilidade que em muito comprometem a consolidação da democracia no país (SANTOS, 1993). Por outro lado, verificou-se, ao mesmo tempo, uma maior mobilização da população indígena, historicamente marginalizada das decisões políticas do país, que passou a reivindicar com maior intensidade o estabelecimento de um governo representativo que seja capaz de atender seus direitos básicos.

\section{A participação política dos povos indígenas vista ao longo do tempo}

Desde os tempos coloniais, a população indígena se viu alijada da esfera política boliviana, situação que não se alterou com a proclamação da independência, quando a elite criolla (descendentes de europeus nascidos na América) rapidamente se estabeleceu no poder, reproduzindo as instituições políticas e os instrumentos jurídicos já vigentes e controlando as grandes propriedades agrícolas, nas quais os indígenas trabalhavam em situações de escravidão - configurando o que, nas palavras de Quijano (2002), constitui-se na colonialidade do

\footnotetext{
${ }^{4}$ Estas redes sociais constituem verdadeiros estoques de capital social, aqui entendido como resultado de certas relações sociais - combinando atitudes de confiança com condutas de reciprocidade e cooperação que proporcionam maiores oportunidades à consecução de certos objetivos - no caso, a geração de renda - que, na sua ausência, não seriam alcançados, ou o seriam com maior dificuldade (ATRIA apud DURSTON, 2003).
} 
poder, ou seja, a associação entre Estados politicamente independentes com sociedades coloniais onde a classificação social baseia-se na etnia dos indivíduos.

O processo de democratização iniciado a partir da Revolução Agrária de 1952 transformou, em parte, o regime de exclusão étnica que imperava até então e contribuiu para que a questão indígena atingisse uma posição de relevo no cenário político boliviano. Esta relativa proeminência foi resultado, em linhas gerais, da adoção do sufrágio universal na Bolívia, que ampliou o direito de cidadania a milhões de indígenas anteriormente marginalizados de qualquer consulta sobre os assuntos políticos do governo, tornando-os, assim, visíveis aos olhos dos políticos devido ao considerável contingente de votos que representavam.

Data desta época, também, a formação de agências de desenvolvimento e de institutos indígenas, que contribuiu para a distribuição de terras e créditos agrícolas e propiciou o fornecimento de subsídios à produção, configurando, contudo, por outro lado, uma nova rede de compensações clientelistas que possibilitou o controle das comunidades indígenas por parte do Estado boliviano (MURRIETA, 2003).

Ao mesmo tempo, a educação formal e gratuita expandiu-se para as áreas rurais e permitiu que os indígenas tivessem um maior acesso a possibilidades de ascensão social. No entanto, percebe-se que a educação foi utilizada, na verdade, como ferramenta de dominação e cooptação dos povos indígenas, uma vez que as matérias eram ministradas unicamente na língua espanhola e buscavam disseminar a religião cristã e os valores intelectuais e morais da cultura européia, em detrimento dos tradicionais costumes indígenas 5 .

De fato, até as décadas de 1950 e 1960, duas importantes correntes ideológicas problematizavam a questão indígena e suas implicações para o desenvolvimento dos países: o liberalismo e o marxismo. Segundo estas duas ideologias, a questão indígena representava um obstáculo para o desenvolvimento da América Latina. Para os liberais, a questão indígena relacionava-se diretamente à

\footnotetext{
${ }^{5}$ Murrieta (2003) argumenta que a educação em língua espanhola contribuiu para a homogeneização cultural e para a estigmatização das tradições indígenas, utilizadas como argumento para a legitimação de práticas de exclusão econômica, política e cultural que perduram até os dias de hoje.
} 
BRUNO SIQUEIRA ABE SABER MIGUEL - A inserção dos movimentos indígenas ...

pobreza e ao subdesenvolvimento nacional, devendo ser superada mediante a educação, a assimilação e o progresso tecnológico. Os marxistas, por sua vez, consideravam os indígenas como uma classe economicamente oprimida, que deveria lutar, assim, em solidariedade com outras classes desfavorecidas ${ }^{6}$. Ou seja, as duas correntes de idéias compartilhavam a mesma indiferença em relação aos problemas étnicos e culturais, considerando a questão indígena na América Latina como um problema puramente econômico (LEE VAN COTT, 1994).

Foi somente a partir da década de 1970 que esta postura ideológica começou a se alterar, quando, sob a influência do pensamento gramsciniano e sua crítica ao reducionismo econômico, reconheceu-se a equivalência entre os fatores materiais - políticos e econômicos - e os elementos culturais, dentro de uma visão integrada da sociedade (ALVAREZ, DAGNINO e ESCOBAR, 2000). A cultura é reconhecida como uma importante dimensão das várias instituições econômicas, políticas e sociais -, e a esfera política passou a ser vista como o campo que envolve uma disputa em torno de um conjunto de significações culturais.

Vale ressaltar, também, o surgimento, nesse período, da teologia da libertação na América Latina, inclusive na Bolívia, que em muito favoreceu a assistência da Igreja Católica aos mais pobres. As missas celebradas nas igrejas católicas nessa época falavam das grandes desigualdades sociais e econômicas que caracterizavam a região, mostrando a América Latina como uma grande pirâmide, onde na base encontrava-se a grande maioria miserável da população, incitando os desfavorecidos - em sua maioria de origem indígena - a organizarem-se para lutar contra a pobreza e a injustiça social (STEPAN, 1988).

Assim, quando em 1982 o governo militar da Bolívia foi substituído por um governo eleito pelo povo, novos grupos da sociedade civil - muitos deles identificados à causa indígena adquiriram crescente relevância no cenário político boliviano, aproveitando as novas oportunidades proporcionadas pela democracia e

\footnotetext{
${ }^{6}$ De fato, os movimentos sociais bolivianos caracterizavam-se, nessa época, por sua clara base sindical estabelecendo-se a divisão entre operariado e burguesia, conforme o pensamento marxista -, na qual a Central Operária Boliviana (COB) congregava grande parte das forças sociais e possuía uma intensa atuação na arena política.
} 
BRUNO SIQUEIRA ABE SABER MIGUEL - A inserção dos movimentos indígenas ...

propondo demandas políticas como o direito a uma cultura própria e uma maior participação nos assuntos políticos.

Dentre esses movimentos, cabe mencionar, para além da Central Operária Boliviana (COB) - que representava, em maior grau, os interesses dos povos indígenas do altiplano boliviano -, a fundação, ainda em 1982, da Confederação dos Povos Indígenas da Bolívia (CIDOB). Congregando 34 comunidades indígenas da região de terras baixas bolivianas (como os chiquitanos, ayoreos, guarayos e guaranis), a CIDOB objetiva fomentar a unidade entre os povos indígenas do oriente da Bolívia para a defesa de seus direitos, especialmente por meio da participação nas decisões políticas, econômicas, sociais e culturais do país, respeitando-se, ao mesmo tempo, as tradições de cada grupo.

No entanto, durante o governo do presidente Víctor Paz Estenssoro, que assumiu o poder em 1985, adotou-se uma postura firme em relação às organizações indígenas, o que enfraqueceu o poder de mobilização da COB e da CIDOB. Implementou-se, também, uma política econômica austera que reduziu os incentivos fiscais até então fornecidos para a população camponesa, o que elevou os níveis de desemprego e gerou um fracionamento social. Este contexto foi marcado pelos baixos índices de confiança nas instituições políticas, especialmente os partidos políticos e o Congresso, refletindo-se, até hoje, na elevada proporção de indivíduos que considera a presença destas instituições desnecessárias para a existência da democracia $59 \%$ e $46 \%$, respectivamente - e no baixo interesse da população pelos assuntos políticos (CALDERÓN, 2007).

A partir de então, com o processo de redemocratização, o cenário de forças local testemunhou um processo de reformulação, reforçado pela reestruturação das relações sociais e pelas conseqüências sobretudo sociais - das políticas neoliberais aplicadas à economia boliviana durante a década de 1990. De fato, é durante este período que se observa de modo mais intenso a ascensão dos movimentos sociais calcados na identidade indígena - diferenciando-se dos movimentos que se singularizavam pela divisão de classes -, que passaram a canalizar as aspirações populares por uma maior representatividade na esfera política e por melhores condições de vida. 
Dois grandes partidos ligados ao movimento indígena passaram a gozar, assim, de considerável proeminência na arena política boliviana, ambos com um claro discurso anti-globalização. Por um lado, o Movimento Índio Pachakuti (MIP), liderado pelo aymará Felipe Quispe, propunha a necessidade da criação de uma nação indígena autônoma que permita a autodeterminação dos povos nativos, optando, desse modo, por uma postura de radicalização política.

O Movimiento ao Socialismo (MAS), por sua vez, encabeçado pelo também aymará Evo Morales, defendia a preservação do Estado boliviano, desde que reformado radicalmente mediante uma maior intervenção estatal na economia. Líder cocaleiro e indígena carismático, a figura de Evo Morales vai projetando-se cada vez mais no cenário político do país, sobretudo pelo papel de liderança que teve nos protestos realizados pelas comunidades indígenas contra a proibição imposta pelo governo às plantações de coca na Bolívia, obtendo, assim, o reconhecimento de larga parcela da população nativa no país, culminando com sua vitória no primeiro turno das eleições presidenciais de $2005^{7}$ e grandes expectativas quanto ao aprofundamento da democracia para os povos indígenas do país.

\section{Cultura, cidadania e as novas oportunidades de participação política}

Conforme dito anteriormente, a maioria dos países latinoamericanos testemunhou, durante a década de 1980, a transição de regimes ditatoriais em direção a sistemas democráticos de governo, processo que foi acompanhado por um verdadeiro renascimento cultural dos povos indígenas, que passaram a almejar uma maior participação política e a questionar as práticas democráticas exercidas pelos governos da região. Em outras palavras, os movimentos indígenas intensificaram sua contestação à democracia representativa - que via na participação popular um obstáculo à consolidação democrática e defendia a restrição da participação popular ao voto e às discussões

\footnotetext{
${ }^{7}$ Vale ressaltar que cerca de 800 mil indígenas foram impedidos de votar na eleição de dezembro de 2005 pela Comissão Nacional Eleitoral (CNE) por não terem votado nas eleições de 2002, o que impediu, muito provavelmente, um contingente de votos ainda maior para Evo Morales.
} 
BRUNO SIQUEIRA ABE SABER MIGUEL - A inserção dos movimentos indígenas ...

relativas à escolha dos líderes políticos (SCHUMPETER, 1942) -, buscando um papel mais ativo nos processos de tomada de decisão e reivindicando um aprofundamento das incompletas reformas empreendidas durante o processo de democratização (O'DONNELL e REIS, 1988).

De fato, a existência do sufrágio universal não configura, automaticamente, a condição de cidadão aos indivíduos, uma vez que a participação política pelo voto não é acompanhada por noções básicas sobre os direitos dos cidadãos e os deveres do Estado, situação na qual muitas vezes predomina a baixa presença governamental, a excessiva burocratização, a persistência do clientelismo e da corrupção e as dificuldades para fazer prevalecer o respeito aos direitos humanos dos povos indígenas. Nestas circunstâncias, não é de se surpreender que a democracia passe a perder sentido para os setores indígenas, que viram suas condições de vida se deteriorarem de maneira dramática com a adoção das políticas neoliberais a partir da década de 1980. Sendo assim, esta situação fomentou um progressivo processo de emergência dos movimentos indígenas nunca antes observado, que pode ser sintetizado a partir de seus traços fundamentais.

Primeiramente, os movimentos indígenas constituíram-se e consolidaram-se como atores sociais coletivos, exigindo 0 reconhecimento de suas identidades específicas e seu direito à participação política. A tradicional configuração fragmentária das reivindicações indígenas começou a ser substituída por redes de contato mais abrangentes, como exemplificam a criação da COB e da CIDOB, com a realização de encontros e ações de coordenação da liderança indígena que propiciaram a construção de um conjunto de propostas de alcance nacional, regional e, até mesmo, internacional (YASHAR, 1998).

As diversas organizações indígenas foram conformando, pouco a pouco, uma rede de organizações de base étnica, desde níveis locais até níveis regionais e nacionais, que articulam uma identidade particular com um programa de democratização nacional. Mais do que a democratização do sistema político, objetiva-se a democratização da sociedade como um todo, superando, portanto, as práticas culturais arraigadas em relações sociais de exclusão e desigualdade. Segundo Alvarez, Dagnino e Escobar (2000), tem lugar, assim, um processo de 
redefinição de conceitos como democracia e cidadania, que passam a apontar para direções que contestam a histórica cultura autoritária mediante a atribuição de um novo significado às noções de direitos, espaços públicos e privados, ética e igualdade, conformando, ao mesmo tempo, definições alternativas do que é considerado como político.

As contestações culturais não são mais vistas como um simples subproduto da luta política; são, ao contrário, componentes dos esforços dos movimentos indígenas para redefinir o sentido e os limites do próprio sistema político e constituem, de modo geral, uma verdadeira política cultural que se faz presente em todos os movimentos sociais latino-americanos da atualidade, numa visão mais ampla que objetiva a defesa da identidade, do pluralismo cultural e da cidadania multicultural dos povos indígenas (GADEA e SCHERER-WARREN, 2005).

Um segundo fator, que pode ser considerado um produto do primeiro, diz respeito ao direcionamento dos protestos informais para a esfera eleitoral: os movimentos indígenas, antes ausentes do processo eleitoral, passaram a participar da concorrência por cargos oficiais, formando partidos políticos para contrastar com a crise de representação das agremiações tradicionais ou envolvendo-se em alianças com os partidos já estabelecidos. Como conseqüência, os movimentos indígenas convertem-se em atores estratégicos dentro do panorama político boliviano, exercendo, pela via institucional, pressões constantes para a consecução de seus interesses ${ }^{8}$ que resultaram na eleição de Evo Morales em 2005.

De acordo com as idéias de Alain Touraine (1997), estes fatores representam a nova configuração dos movimentos indígenas latinoamericanos, que têm articulado um universo simbólico - marcado por uma legítima demanda pelo reconhecimento e pela afirmação da identidade cultural indígena - com um universo instrumental - marcado pela luta por garantias institucionais de representação política dos indivíduos -, estabelecendo, assim, um diálogo entre o sujeito social e a democracia onde a ampliação de um contribui para o fortalecimento do outro. Em consonância com os debates acerca da noção de democracia participativa, Touraine (1997) argumenta que o sistema democrático

\footnotetext{
${ }^{8}$ Data de 1993 a primeira grande vitória do movimento indígena boliviano, quando Víctor Hugo Cárdenas foi eleito vice-presidente do país.
}

Espaço Ameríndio, Porto Alegre, v. 2, n. 1, p. 68-84, jan./jun. 2008. 
BRUNO SIQUEIRA ABE SABER MIGUEL - A inserção dos movimentos indígenas ...

não se limita somente ao conjunto de disposições institucionais formais, devendo garantir a luta dos sujeitos sociais, de acordo com sua cultura e contra a lógica de dominação do sistema social. Sendo assim, a democracia deve criar espaços públicos para a participação dos cidadãos e, ao mesmo tempo, assegurar o respeito às diferenças e ao pluralismo cultural dos indivíduos (GADEA e SCHERER-WARREN, 2005).

De acordo com Habermas (1997), esses espaços públicos podem ser descritos como uma rede adequada para a comunicação de conteúdos e para tomadas de posição e opiniões, no interior dos quais os fluxos comunicacionais são filtrados e sintetizados a ponto de constituírem opiniões públicas acerca de temas específicos.

Para o autor, os espaços públicos

têm que reforçar a pressão exercida pelos problemas, ou seja, ele não pode limitar-se a percebê-los e a identificá-los, devendo, além disso, tematizá-los, problematizá-los e dramatizá-los de modo convincente e eficaz, a ponto de serem assumidos e elaborados pelo complexo parlamentar (HABERMAS, 1997, p. 91).

Avritzer (2002) afirma que o processo de democratização mediante a constituição de espaços públicos onde a sociedade civil participa em condição de igualdade com seus representantes políticos no desenvolvimento de iniciativas em cooperação com e em prol da sociedade - possibilita, em parte, a superação da dicotomia existente entre elite e povo, a partir da interação direta e pela livre expressão e associação dos participantes dos espaços públicos, capazes de levarem à arena política o debate acerca de questões outrora negligenciadas e formando verdadeiros fóruns de deliberação pública.

Os espaços públicos romperiam, assim, com a visão weberiana que rejeita a possibilidade da participação popular na administração pública. Segundo Avritzer (2002), essa esfera de discussão possibilita aos movimentos sociais, na verdade, um canal para a formulação de estratégias que visam tornar as autoridades políticas mais sensíveis às deliberações lá empreendidas, redefinindo os padrões políticos e ampliando o escopo da ação social no sistema democrático. Em outras palavras, verifica-se uma verdadeira revisão da relação entre Estado e sociedade, ainda em lenta construção na Bolívia, criando-se espaços de 
BRUNO SIQUEIRA ABE SABER MIGUEL - A inserção dos movimentos indígenas ...

participação que possibilitam o aprofundamento da democracia nos quais os cidadãos passam a desempenhar funções antes reservadas ao Estado.

Por fim, a própria análise das eleições presidenciais da Bolívia se faz importante, uma vez que o período entre 1982 a 2002 corresponde a um momento fundamental para a consolidação da democracia boliviana, com o esgotamento dos personagens políticos relacionados ao regime ditatorial outrora vigente.

Em síntese, o movimento indígena boliviano passou a adotar uma postura que almeja a ampliação do político, a transformação das práticas estatais dominantes, o aprofundamento da cidadania e a inserção de atores sociais, até então excluídos, no interior do sistema político, de modo a institucionalizar a diversidade cultural que caracteriza o país. Como afirma Lechner (1988, p. 34), à respeito dos processos de democratização da América Latina,

a atual revalorização dos procedimentos e instituições formais da democracia não pode apoiar-se em hábitos estabelecidos e normas reconhecidas por todos. Não se trata de restaurar normas regulatórias, mas de criar disposições constitutivas da atividade política: a transição exige a elaboração de uma nova gramática social (LECHNER, 1998, p. 34).

No entanto, apesar dos progressos alcançados pelo movimento indígena boliviano - propiciado, principalmente, pelo investimento público em programas sociais de combate à pobreza -, a posse de Evo Morales no cargo de presidente do país trouxe consigo inúmeros desafios, cujas soluções ainda não são facilmente identificáveis e refletem, em parte, as grandes expectativas geradas a partir de sua eleição.

\section{Os limites da democracia boliviana}

Uma das questões fundamentais para a consolidação da democracia boliviana consiste, sem dúvida, no enfrentamento da considerável distância histórica existente entre as instituições políticas e 
BRUNO SIQUEIRA ABE SABER MIGUEL - A inserção dos movimentos indígenas ...

os processos sociais do país. O novo governo precisa, assim, realizar mudanças institucionais capazes de envolver a sociedade nos diferentes níveis decisórios, superando o quadro de reduzida confiança em relação às instituições políticas - 31\% dos bolivianos confiavam nos partidos políticos, em 2006 (SCHWARZ-BLUM, 2006) - e de baixa participação de grande parte da população, o que pode servir de base de apoio, eventualmente, para a implementação de políticas francamente conservadoras (MOISÉS e ALBUQUERQUE, 1989).

Nesse sentido, após eleito, Evo Morales realizou uma ampla consulta junto às organizações sociais, sobretudo os movimentos indígenas, para a formação de seu gabinete de ministros, composto, em sua maioria, por indígenas, camponeses e dirigentes sindicais - visto por críticos como uma forma de cooptação dos líderes sociais -, na busca de um novo modelo econômico que substitua a predominância das políticas neoliberais por uma economia mista com grande presença do Estado.

As resistências, no entanto, não são poucas, e a continuidade de um regime de governo com poucos canais de participação democrática, basicamente restritos às eleições e referendos, contribui para a manutenção do impasse. Conforme exposto ao longo do trabalho, a fragmentação boliviana não está somente na divisão do país em nove departamentos, quatro deles claramente oposicionistas, e tampouco na cor da pele da população indígena, mestiça e branca, mas, sobretudo, nos movimentos sociais de cunho indígena que marcam o país e que foram decisivos para os diversos episódios de instabilidade política e para a eleição de Evo Morales no primeiro turno das eleições de 2005.

Atualmente, além da tradicional oposição procedente de Santa Cruz de la Sierra, que luta pela autonomia do departamento que concentra grande parte da produção econômica do país, antigos aliados esperam que o governo de Evo Morales - devido à própria origem indígena do presidente - seja capaz de atender imediatamente algumas das principais reivindicações populares, sob a ameaça de realizarem protestos sociais que podem colocar em risco a estabilidade do novo governo. Nesse sentido, como tentativa de equilibrar o perfil de seu ministério e evitar protestos contra seu governo, o presidente nomeou, 
BRUNO SIQUEIRA ABE SABER MIGUEL - A inserção dos movimentos indígenas ...

recentemente, um gabinete mais técnico, ainda que sem representantes do departamento de Santa Cruz.

De modo geral, os desafios para a consolidação da democracia boliviana, considerando-se a especificidade da presença de um presidente de origem indígena no poder, podem ser sintetizados em torno dos seguintes temas:

(i) gás natural - apesar da Bolívia possuir a segunda maior reserva de gás natural da América do Sul, esta riqueza natural não se traduz em melhorias socioeconômicas para a grande maioria da população, que já realizou inúmeros protestos relacionados a essa questão. Evo Morales nacionalizou a indústria de hidrocarbonetos, mas precisará dar garantias às companhias de petróleo estrangeiras de que não realizará futuras expropriações, equilibrando o controle estatal com a necessidade de atrair investimentos externos, decisivos para o crescimento econômico e o desenvolvimento do país.

(ii) drogas - a Bolívia é a terceira maior produtora mundial de coca, matéria-prima para a produção de cocaína, o que faz do país um importante ator na iniciativa norte-americana de erradicação das plantações de coca. Ex-líder cocaleiro, Morales é a favor da descriminalização do uso da coca e encoraja seu uso legal em produtos como o chá, característicos da tradição indígena boliviana.

(iii) relações exteriores - identificado com líderes que adotam uma clara postura de oposição aos Estados Unidos, como Hugo Chavez, da Venezuela, Evo Morales tem o desafio de estabelecer um diálogo construtivo com os norte-americanos - o país é o segundo maior parceiro comercial da Bolívia - sem entrar em choque com os setores mais radicais dos movimentos indígenas.

(iv) divisões regionais - os departamentos de Santa Cruz de la Sierra, Beni, Pando e Tarija lideram uma campanha por maior autonomia e o governo de Evo Morales tem adotado, em contrapartida, medidas que limitam os poderes dos governadores, o que pode contribuir para o acirramento da oposição política ao presidente. Essa divisão se fez presente já no estabelecimento da Assembléia Constituinte, em 2006, quando os departamentos de oposição ao governo central, com forte apoio dos movimentos sociais locais, exigiram a fixação de um quorum de dois terços dos parlamentares constituintes para a aprovação dos 
artigos da nova Constituição, enquanto os aliados de Evo Morales reivindicavam uma maioria simples dos congressistas para tanto; o imbróglio perdurou por vários meses, até decidir-se pela adoção da maioria qualificada na votação dos artigos, como queria a oposição ${ }^{9}$.

Mais recentemente, em maio de 2008 , foi realizado referendo em Santa Cruz no qual cerca de $85 \%$ da população local aprovou o estatuto autonômico do departamento - que prevê, por exemplo, a autonomia de Santa Cruz para arrecadar impostos e definir suas políticas nas áreas de educação e saúde -, decisão rechaçada como ilegal por La Paz e que resultou em vários choques entre oposicionistas e partidários do governo de Evo Morales.

(v) pobreza - aproximadamente dois terços da população da Bolívia - e $80 \%$ dos habitantes de origem indígena - vivem na pobreza, acentuada após as medidas de cunho neoliberal adotadas como mecanismos para estimular o crescimento econômico do país. Além disso, os níveis de analfabetismo e de mortalidade infantil são maiores entre a população indígena, o que traz uma grande expectativa em torno das promessas feitas por Evo Morales para superar esta situação durante a campanha eleitoral.

A pergunta que se faz, então, é se o governo de Evo Morales será capaz de administrar o Estado e controlar os diversos interesses existentes diante desses novos e velhos dilemas presentes na sociedade boliviana, considerando-se, ao mesmo tempo, a identidade cultural indígena de grande parte dos habitantes da Bolívia e, também, de seu presidente, como um importante traço definidor do cenário político, econômico e social do país.

\section{Considerações finais}

Segundo Touraine (1997, p. 285), "não há democracia sem o reconhecimento da diversidade entre as culturas e da dominação que existe entre elas". Nesse sentido, pode-se observar que, na Bolívia, o movimento indígena vem combinando lutas por sua inserção na arena

\footnotetext{
${ }^{9}$ Caso não se alcance o contingente estipulado, um referendo popular será realizado para se decidir pela aprovação ou não do artigo constitucional.
} 
BRUNO SIQUEIRA ABE SABER MIGUEL - A inserção dos movimentos indígenas ...

política com as lutas contra a discriminação étnica e pelo reconhecimento de suas raízes históricas e especificidades culturais.

Assim, e diante de tudo o que foi exposto no decorrer do trabalho, pode-se concluir que o movimento indígena boliviano - ao destacar a transformação das relações políticas, econômicas e sociais, bem como a alteração das práticas culturais presentes no interior da sociedade como essenciais para a construção e a consolidação de uma verdadeira democracia - percebe que sua política cultural pode e deve prolongar-se às esferas políticas representativas formais.

Nesse sentido, a eleição, pela primeira vez na história da Bolívia, de um líder indígena para o cargo de presidente boliviano trouxe consigo a esperança e a responsabilidade de que o país testemunhará uma nova fase em sua história, na qual o estabelecimento de políticas públicas e de reformas institucionais favorecerá a superação da condição de marginalidade das comunidades indígenas no cenário político, econômico e social boliviano. Para tanto, será preciso um verdadeiro pacto social com os diversos setores e interesses da sociedade, dos mais radicais aos mais conservadores, sob o risco de um novo ciclo de convulsões sociais e instabilidade política. Contudo, o que se verifica, até o momento, é uma contínua deterioração das relações do presidente com os departamentos que lhe fazem oposição, ao mesmo tempo em que a criação de espaços públicos de aprofundamento da democracia é preterida em detrimento de políticas sociais com questionáveis propósitos eleitorais.

\section{Referências bibliográficas}

ALVAREZ, Sonia; DAGNINO, Evelina; ESCOBAR, Arturo. Cultura e política nos movimentos sociais latino-americanos: novas leituras. Belo Horizonte: Editora UFMG, 2000.

AVRITZER, Leonardo. Democracy and the public space in Latin America. Princeton: Princeton University Press, 2002.

CALDERÓN, Fernando. Tiempos de agitación, tiempos de cambio: sociedad y democracia en los países andinos meridionales. In: SORJ, Bernardo; OLIVEIRA, 
Miguel Darcy de. (Orgs.). Sociedad civil y democracia en América Latina: crisis y reinvención de la política. Rio de Janeiro: Ediciones Centro Edelstein, 2007. p. 153-204.

DURSTON, John. Capital social: parte del problema, parte de la solución, su papel en la persistencia y en la superación de la pobreza en América Latina y el Caribe. In: ATRIA, Raul (Org.). Capital social y reducción de la pobreza en América Latina y el Caribe: en busca de un nuevo paradigma. Santiago do Chile: Comisión Económica para América Latina y el Caribe/University of Michigan Press, 2003. p. 147-202.

FERNÁNDEZ, Rodrigo. Inequidad, ciudadanía y pueblos indígenas en Bolívia. Santiago de Chile: CEPAL, 2004.

GADEA, Carlos; SCHERER-WARREN, Ilse. A contribuição de Alain Touraine para o debate sobre sujeito e democracia latino-americanos. Revista de Sociologia e Política, Curitiba, n. 25, p. 165-175, nov. 2005. Disponível em: http://redalyc.uaemex.mx/redalyc/pdf/238/23802505.pdf . Acesso em: 22 jun. 2008.

HABERMAS, Jürgen. Direito e Democracia: entre facticidade e validade. Rio de Janeiro: Tempo Brasileiro, 1997.

INE - Instituto Nacional de Estadísticas. Censo Nacional de Poblacíon y Vivienda. La Paz: INE, 2001.

LECHNER, Norbert. Los Patios Interiores de la Democracia. México: Fondo de Cultura Economica, 1988.

LEE VAN COTT, Donna. Indigenous peoples and democracy in Latin America. New York: St. Martin's Press, 1994.

MOISÉS, José A.; ALBUQUERQUE, José A. G. Dilemas da consolidação da democracia. Rio de Janeiro: Editora Paz e Terra, 1989.

MURRIETA, Julio R. Democracia y participación política de los pueblos indígenas en América Latina. Paris: UNESCO, 2003.

O’DONNEL, Guillermo; REIS, Fábio W. A democracia no Brasil: dilemas e perspectivas. São Paulo: Editora Vértice, 1988.

QUIJANO, Anibal. Colonialidade, poder, globalização e democracia. Novos Rumos, São Paulo, v. 17, n. 37, p. 4-28, 2002. Disponível em: http://www.seed.pr.gov.br/portals/portal/usp/primeiro_trimestre/textos/hemeroteca/nor/ nor0237/nor0237_02.pdf. Acesso em: 22 jun. 2008.

SANTOS, Wanderley G. dos. Razões da desordem. Rio de Janeiro: Hucitec, 1993.

SCHWARZ-BLUM, Vivian. Por que confiamos nas instituições? O caso boliviano. Opinião Pública, Campinas, v. 12, n. 2, p. 27-45, nov. 2006. 
BRUNO SIQUEIRA ABE SABER MIGUEL - A inserção dos movimentos indígenas ...

SCHUMPETER, Joseph A. Capitalism, socialism and democracy. New York: Harper \& Row, 1942.

STEPAN, Alfred. Democratizando o Brasil. Rio de Janeiro: Editora Paz e Terra, 1988.

TOURAINE, Alain. ¿Podremos vivir juntos? Iguales y diferentes. Buenos Aires: Fondo de Cultura Económica, 1997.

YASHAR, Deborah. Contesting citizenship: indigenous movements and democracy in Latin América. Comparative Politics, v. 31, n. 1, p. 23-42, out. 1998. 